\title{
The Trade Policy of Emerging Countries*
}

\section{by Marianna Restum Antonio de Albuquerque}

Universidade Estadual do Rio de Janeiro, Brazil

(Mahrenbach, Laura Carsten. The Trade Policy of Emerging Countries: Strategic Choices of Brazil and India. Londres: Palgrave Macmillan, 2013)

As the World Trade Organization (WTO) and its predecessor, the General Agreement on Tariffs and Trade (GATT) has stimulated the access to new markets and enhanced the basis of non-discrimination and reciprocity in trade policies, it is easy to consider that this new economic and commercial order has been beneficial to emerging powers. These countries were able to expand their domestic productions and compete on more equal terms with developed countries. In her book, "The Trade Policy of Emerging Countries: Strategic Choices of Brazil and India", Laura Carsten Mahrenbach departs from these assumptions, and instead pursues the objective of analyzing how domestic variables, such as economic interests and political ideas, are reflected in strategic choices made by two emerging powers, Brazil and India, in WTO negotiations.

To properly meet this task, the author divides the book into three main parts. Chapter 01 introduces methodological considerations and presents the research puzzle and main arguments; Chapters 02 through 05 applies the arguments and the domestic variables to Brazil's and India's behavior in the WTO, regarding trade liberalization and dispute settlements; and chapter 06 concludes by presenting the main findings, proposing a revised framework and summarizing new possibilities of research. In terms of methodological contribution, one of the most valuable accomplishments of Mahrenbach's societal approach to fill a gap in theoretical studies that underestimated the role of domestic actors in trade policies. Also, the research design is clear and complete, and could be used as a model for further studies. However, a question that 
remains unaddressed and surpasses all the content of the book is the starting point based on the premise of the rational actor. The state is described as an agent that is primarily motivated by self-interest and that calculates means and ends in the decisionmaking process. This premise can be uncomfortable to those scholars who do not share this commitment. The author believes that rational action should not be an assumption per se, since governments evaluate costs and benefits before choosing an option to follow, but there are many studies that challenge the predominance of rational calculus as the main mechanism for decision making. In Foreign Policy Analysis, for instance, some authors (such as SPROUT and SPROUT, 1956) consider that actions can be irrational due to psychological aspects of the leader, to incompatible foreign policy objectives, to misperceptions and miscalculations about the other partner, and so on. To scholars who consider these subjective aspects as possible interferences in the decisionmaking process, Mahrenbach's focus on rational calculation can be problematic.

Through Chapter 01, the author presents the research design, the main arguments and how the variables are operationalized. Based on the societal approach, which draws from elements of liberalism, the focus of Mahrenbach is on the domestic sources of governmental decision. As such, she considers that the independent variables are domestic preferences, and she divides these domestic mechanisms into two categories: economic interest and political ideas. The economic interests are subdivided into liberalization, protection, economics, cooperation and economic isolation, and the political ideas are influence, neutrality, affiliation and autonomy. The combination of these aspects with the degree of government responsiveness to these stimuli can result in three strategies: substitution, reform and simple use of the WTO structure. The author includes a control variable, described as the government reaction to trade policies outside the scope of the WTO, to compare and verify the usefulness of the model. Following this path, she develops four cross-issue main arguments, combining the preeminence of each domestic aspect with the strategy chosen. Argument 01 claims that when economic interests dominate, the governments will choose substitution or simple use; Argument 02 states that when political ideas dominate, governments will choose substitution or reform.

In chapters 02 through 05, the author empirically tests these above-mentioned arguments, applying them to case studies that happened with Brazil and India since the start of the Doha Round. The cases are divided into trade liberalization situations and 
dispute settlement within the WTO board. Chapters 02 and 03 are about the Brazilian case, and Chapter 03 and 04 are about the Indian case. These divisions between countries, and not between issues, undermine the comparative dynamics, as the conclusions are only presented as a whole in the final chapter. However, the author tries to go back and forth to link the discussion and fill this gap. Despite being included as parts of the same category - as emerging powers - it is always reaffirmed that both countries possess differences as well. To tackle this problem, Mahrenbach has also created sub-arguments to adapt Arguments 01 and 02 to the specificity of the two studied countries, and these applied arguments are presented in the beginning of each empirical chapter.

In the first empirical chapter (chapter 03) the author employs three qualitative methods - discourse analysis, public opinion polls and expert interviews - to interpret the relationship between domestic incentives and government behavior in two cases regarding Brazilian trade negotiation. The first case is the WTO mini-ministerial negotiations that took place in 2008 , and the second is the negotiation regarding the establishment of the Free Trade Area of the Americas, between 2001 and 2005. In the first situation, Mahrenbach offers a detailed description of how Argument 01 turned out to be confirmed. The author showed a high level of correlation between the statements made by representatives of economic groups interested in the reform, such as agriculture and automobile industries, and the statements made by government officials. Since this was a case in which economic interests dominated over political ideas, Argument 01 was confirmed because Brazil opted to simply use the structure of the WTO (and did not try to substitute or reform it). In the second case, the main political idea expressed in poll data was "influence", an idea that was connected to substitution and reform and that was only reflected to a moderate degree in government positions. This imbalance between responsiveness to economic interests and to political ideas is one of the challenges that the author tries to disentangle in the final chapter.

The second empirical chapter (chapter 03) deals with Brazilian participation in the Dispute Settlement Board, specifically with two prominent cases: the cotton dispute with the United States and the bilateral licensing dispute with Argentina. It is not possible to present specific details about each quarrel, but in sum, the cotton dispute confirmed Argument 01, as Brazil was comfortable with the board's solution and the dominant strategy was simple use. Once again, the government was more responsive to 
economic interests than to political ideas (that favored influence), and the author gives a tentative explanation related to the role played by lobbies organizations inside Brazil, concentrating demands, that were opposed to the fluidity of public opinion. In the license question with Argentina, it is valuable to highlight how ideational preferences were almost absent from governmental discourse. The author, then, provides a hypothesis about differences in responsiveness when it comes to regional matters.

Turning to the Indian case, chapters 04 and 05 are constructed in parallel with 02 and 03. Chapter 04 describes Indian trade liberalization cases and chapter 05 presents its participation in the Dispute Settlement Board. In chapter 04, the first case retakes the WTO mini-ministerial negotiations, also supporting Argument 01, indicating that the strategy of simple use is employed when economic interests prevail. There was a high level of responsiveness to economic interests and a medium degree to political ideas, a situation similar to the Brazilian process. In the second case, the 2003 free trade agreement between India and the Association of Southeast Asian Nations (ASEAN) was analyzed. The correlation of discourses showed that the Indian government was more responsible to economic interests than to political ideas, and the author explains this gap based on the high level of sectoral mobilization in India. Argument 01 is also confirmed, because it states that the dominance of economic interest could lead to either simple use or substitution, and the latter applied in the Indian-ASEAN agreement.

The last empirical chapter (chapter 05) reported how Indian responsiveness behaved in the Dispute Settlement Board. The first case, about tariff preferences to emerging countries, emerged after a concession made to Pakistan. Argument 01 is confirmed, due to the primacy of response to economic interests and the strategy of simple use, but Mahrenbach makes a concession to show that the connection was less clear, since there was not a clearly defined group mobilization that could domestically base this high correlation. The second case was about the South Asian Free Trade Associations (SAFTA) implementations dispute, and again the main dispute was with Pakistan. The author also puts forward a possibility of distortions that could be traced to regional affairs, as happened in the Brazilian-Argentinian case. The third case dealt with the Indian reaction to the reform of the body itself, especially the demand to include representatives of developing countries. This was the only case where it was possible to test Argument 02, since political ideas were dominant over domestic interests. 
Argument 02 was confirmed, because both ideational preferences and government discourse favored the strategy of reform.

In the final chapter (chapter 06), the author summarizes the main findings, mostly related to the primacy of domestic interest and the strategies of simple use. It is only in the last chapter that Mahrenbach points more directly to the differences and similarities between Brazil and India. She indicates that, surprisingly, the political idea of autonomy is mostly absent in both cases, and points out that the regional context is more likely to interfere in Brazil's behavior than in the Indian case. She also goes back to the arguments and reformulates the framework based on the findings, opening new possibilities of future research. Some examples of open and unexplored pathways are the relationship between partner choice and forum choice, the concept of emerging powers itself, and the applicability of International Relations Theory. In the appendix, the author presents a list of the interest groups and the personalities that were considered and interviewed, but she gives no further explanation of the criteria used to select them.

This book provides a comprehensive description of both the trade liberalization process and how the WTO provided new opportunities to emerging powers, and this alone could have placed it on a good spot in trade policies literature. Notwithstanding, it goes beyond, presenting a well-developed model that combines qualitative mechanisms, such as discourse analysis, with quantitative methods, such as correlation. The relation between clearly-stated variables and arguments make this work an inspiration for scholars trying to build models of social science investigation. It is important to highlight the pertinence of the selected countries, since both are mandatory interlocutors in trade policies and there are not many works that deeply analyze them comparatively.

The few critiques that could be raised are mostly related to the organization of chapters that overshadowed the comparative dimension, which was relegated to the conclusion, and the premise of the rational actor. There is a long line of foreign policy analysts that challenge this view, showing that cognitive and social aspects do matter when the decision-making process is at stake (these studies were influenced by the classical work of SPROUT and SPROUT, 1956). Also, by relating automatically to liberalism and shifting the focus to the domestic sphere, the author denies that there are international and geopolitical elements that constrain domestic options. Foulon (2015), for instance, shows some examples of how a predefined geopolitical structure can limit 
the state's opportunities in the international system. Despite these minor issues, Mahrenbach's book is a masterpiece and is highly competent to fill the gap in the study of emerging powers' trade policies. It is a mandatory book for anyone interested in understanding the functioning of the WTO, how emerging countries can use it as a trade tool and how domestic actors work in Brazil and India.

\section{References}

FOULON, Michiel (2015), Neoclassical realism: challengers and bridging identities. International Studies Review. Vol. 17, № 04, pp. 635-661.

SPROUT, Harold Hance and SPROUT, Margaret Tuttle (1956), Man-millieu relationship: hypothesis in the context of international politics. New Jersey: Centre of International Studies. $101 \mathrm{pp}$. 